\title{
Viron kielen historiaa ja paljon suomenkin ${ }^{1}$
}

Jussi Ylikoski

Külli Prillop, Karl Pajusalu, Eva Saar, Sven-Erik Soosaar ja Tiit-Rein Viitso: Eesti keele ajalugu. Eesti keele varamu VI. Tartu: Tartu Ülikooli Kirjastus 2020. 420 s. ISBN 978-994903-541-0.

Tartu Ülikooli Kirjastus on julkaissut vuodesta 2015 lähtien kirjasarjaa Eesti keele varamu. Sarjassa on kuuden vuoden aikana ilmestynyt jo kuusi perusteellista viron kieltä käsittelevää käsikirjaa, joilla on pituutta yhteensä lähes kolme tuhatta sivua. Oikeastaan sarjan kaikki osat - fonetiikasta ja fonologiasta syntaksiin ja murteiden kielioppiin - ansaitsisivat esittelyn myös suomenkielisille lukijoille, mutta tässä arviossa keskityn sarjan osista ajankohtaisimpaan, vuonna 2020 ilmestyneeseen Eesti keele ajaluguun.

Külli Prillopin, Karl Pajusalun, Eva Saaren, Sven-Erik Soosaaren ja Tiit-Rein Viitson teos on ensimmäinen kattava kokonaisesitys viron kielen kehityksestä, joka tietysti on suurelta osin myös suomen kielen menneisyyttä. Tämä kolmea tutkijasukupolvea edustavan kirjoittajan yhteisponnistus on verrattavissa Lauri Hakulisen korvaamattomaan mutta vanhentuneeseen Suomen kielen rakenteeseen ja kehitykseen, jonka ensimmäinen painos ilmestyi jo 80 vuotta sitten (Hakulinen 1941). Hakulisen teoksen tapaan Eesti keele ajalugu on enemmänkin perusteellinen käsikirja kuin nopeasti lukaistava oppikirja, mutta se sopii myös mainioksi lisälukemistoksi niille, jotka haluavat täydennystä ja päivitystä tietoihin, joita esimerkiksi Tapani Lehtisen (2007) jo ilmestyessään hieman vanhentunut kielihistorian oppikirja esittää (ks. Saarikivi 2011).

Eesti keele ajalugu on erityisen merkittävä virstanpylväs myös siksi, että virolaisesta kielitieteestä on paljolti puuttunut fennistiikalle ominainen nuorgrammaattinen tutkimusperinne, jonka ansiosta useimpien suomen murteiden äänne- ja muotohistoria on tunnettu varsin yksityiskohtaisesti jo pitkään. Virolaiset tutkijat ovat korostaneet suomalaisten merkitystä myös viron kielen historian tutkimuksessa (esim. Rätsep 1994; Kasik 2011: 117-118; Eesti keele ajalugu s. 63-65). Virittäjän viettäessä 125-vuotisjuhliaan

\footnotetext{
${ }^{1}$ Viimeinen taittamaton käsikirjoitusversio kirja-arvostelusta, joka on ilmestynyt Virittäjässä 125 s. 604-610. https://doi.org/10.23982/vir.111545
} 
onkin syytä panna merkille, että etenkin lehden historian alkupuolella viron tutkimus oli erottamaton osa "yhteissuomalaista" kielentutkimusta, ei niinkään suomen sukukielen tutkimusta. Erityisen hyvän kuvan viron kielen roolista Virittäjässä saa Eeva Niinivaaran (1961, 1982, 1991) kokoamista bibliografioista, jotka osoittavat lehden 94 ensimmäisen vuosikerran sisältävän yli 500 Viro-aiheista kirjoitusta parilta sadalta kirjoittajalta.

\section{Vanhaa historiaa ja uusinta uutta}

Teos koostuu neljästä osasta: johdannosta, historiallisesta fonologiasta, historiallisesta morfologiasta ja kantasanojen historiasta. Temaattisesti monipuolisin on yli 50-sivuinen johdanto-osa, jonka aloittaa Karl Pajusalun katsaus viroon uralilaisena ja itämerensuomalaisena kielenä; tätä seuraa kirjan oppikirjamaisimpana osuutena Külli Prillopin ja Tiit-Rein Viitson kuvaus kielihistorian tutkimusmenetelmistä ja peruskäsitteistä. Johdannon päättää Pajusalun ja Eva Saaren tiivis mutta kattava yleisesitys viron kielihistorian tutkimushistoriasta. Teoksen pääosan muodostavat Prillopin liki sadalla sivulla esittämä viron historiallinen fonologia sekä lähes yhtä pitkä Prillopin ja Saaren kuvaama historiallinen morfologia. Sanaston historian esittelee lyhyemmin Sven-Erik Soosaar.

Eesti keele ajalugu kuvaa viron kielen kehityksen niin pitkällä ajanjaksolla kuin mihin vertaileva kielitiede on tähän mennessä luotettavasti yltänyt. Tästä syystä huomattava osa teoksesta käsittelee koko itämerensuomen historiaa kantauralista nykykieliksi, kukin pääluku omalla tavallaan.

Vaikka historiallinen fonologia tavallisessa säännönmukaisuudessaan soveltuu hyvin systemaattisen, jopa atomistisen kuvauksen kohteeksi, kaiken kattava matka kantauralista viron murteisiin olisi kohtuuttoman pitkä ja kuoppainenkin. Johdantoa seuraava Prillopin kirjoittama fonologinen pääluku on jaettu kronologisesti itämerensuomen yhteiseen historiaan sekä viron erilliskehitykseen, joka jaetaan 1200-luvulla päättyneeseen muinaisvirolaiseen (vanaeesti) aikaan, 1200-luvulta 1600-luvulle jatkuneeseen germaanisten kielten värittämään murrosaikaan (murrangueesti) ja sitä seuranneeseen uuden ajan viroon (uuseesti). Eesti keele ajalugu ei kuitenkaan pyri kuvaamaan juuri mitään kielimuotoa kokonaisina rekonstruktioina, vaan kielen kehityskausia esitellään lukuisten keskeisiksi katsottujen äänteenmuutosten valossa. Esitys on siis sisällöltään valikoiva, vaikka se onkin ajallisesti paljon laajempi kuin esimerkiksi Kettusen (1917) uraauurtavassa viron äännehistoriassa myöhempine 
laajennettuine painoksineen. Viron ominaisluonteen ja nähdäkseni myös kirjoittajan oman tutkijaprofiilin vuoksi erityisesti prosodiset kysymykset saavat verrattomasti enemmän huomiota kuin vastaavat teemat suomen kielen historian kuvauksissa.

Ikiaikaisten kirjallisten dokumenttien puuttuessa on selvää, että meillä on varsin vähin varmoja tietoja siitä, miten kantaurali on muuttunut kantasuomeksi ja edelleen viroksi. Vaikka kirjan kullakin osalla on erikseen mainitut kirjoittajansa, monipuolisen kirjoittajakunnan yhteistyö lienee vaikuttanut siihen kätevään ratkaisuun, että kirjassa esitetään erillisinä täydentävinä kokonaisuuksina kaikkiaan 15 numeroitua 1-13-sivuista tietoiskun kaltaista lisäystä (lisa) kysymyksistä, joissa tutkijat eivät ole saavuttaneet konsensusta tai joiden osalta uusimmat näkemykset ovat niin tuoreita, että niihin ei ole vielä ehditty ottaa kunnolla kantaa. Valtaosa tällaisista lisäyksistä pohtii juuri äännehistorian kysymyksiä, ja onkin ilahduttavaa, että tällaiseen klassikoksi muodostuvaan käsikirjaan ovat löytäneet tiensä muun muassa tuoreimmat pohdinnat niinkin klassisista aiheista kuin kantasuomen ensitavun *e:n olemassaolo, varhaisempien kantakielten jälkitavujen vokaalit sekä $* t>(* c i>) * s i$-muutos ja siihen liittyen kantasuomen mahdollinen ${ }^{*} c$-affrikaatta.

Toisin kuin äännehistoria, historiallinen morfologia on rajattu ja jäsennelty jakamalla muutokset kantasuomalaisiin muutoksiin, myöhäiskantasuomen rekonstruktioon ja siitä nykyviroon johtaneisiin muutoksiin. Kuvauksen materiaalisena kohteena eivät ole fonologialuvun tapaan vain irralliset mutta keskeiset muutokset, vaan periaatteessa koko verbi- ja nominitaivutuksen kehitys. Täydellisyydestä ei kuitenkaan muuten voi puhua, sillä historiallinen morfologia tarkoittaa tässä teoksessa vain taivutuksen historiaa. Vaikka johtamisen kehityksen systemaattinen kuvaus olisikin suorastaan mahdotonta, hienoinen harmi on se, että keskeisetkin johtimet on rajattu koko kirjan ulkopuolelle. Korvikkeeksi jää lähinnä Laanestin (1982) vanha yleiskuvaus itämerensuomen äänne- ja muotohistoriasta, mutta tilannetta lievittää myös Eesti keele varamu -sarjan aloittanut Reet Kasikin (2015) erinomainen viron sananmuodostuksen synkroninen kuvaus, jota voi lämpimästi suositella myös suomen johto-opin tutkijoille.

Taivutusmorfologian kuvaus sinänsä on onnistunut synteesi vanhoista totuuksista ja niiden uusimmista haastajista. Kuten kantasuomen ja muiden mahdollisten kantakielten osalta yleisemminkin, nominien ja erityisesti substantiivien taivutus ja taivutuksen kehitys näyttäytyvät selvempinä kuin verbien historiallinen morfologia. 
Kirjan päättää tiivis kuvaus viron kantasanojen historiallisista kerrostumista aina uralilaisesta kantakielestä myöhäisiin nykynaapureilta saatuihin lainasanoihin ja kansainvälisiin vierassanoihin. Aineistopohjana on sinänsä melko konservatiivinen Eesti etümoloogiasõnaraamat (Metsmägi ym. 2012), jonka laatijoihin Sven-Erik Soosaar itsekin kuuluu. Sanastoluvun lopussa on joukko laskelmia eri sanakerrostumista, joista suomalaista kiinnostavat muun muassa viron pari sataa vakiintunutta suhteellisen tuoretta suomalaislainaa (esim. verbit ahistama, masendama, solvama, ööbima; uudempina tulokkaina mm. kaamos, longero ja pomo), joita on Suomenlahden ylitettyäänkin viitisen kertaa enemmän kuin esimerkiksi ikiaikaisilta rajanaapureilta saatuja latvialaislainoja (esim. kanep 'hamppu', kauss 'kulho', kuut 'koppi', lääts 'linssi' ja täkk 'ori').

\section{Sopii suomalaisellekin}

Eesti keele ajalugu on verraton tietolähde etenkin viron kielen tutkijoille, mutta suorastaan odottamattoman hyvä apuneuvo myös suomen kielen tutkijoille ja opiskelijoille. Jos oma kielitaito tuntuu vähäiseltä, kirjaa voi suositella jo yksin tämän ongelman poistamiseen, sillä Eesti keele ajalugu kuvaa nimenomaan viron kieltä viroksi. Koko esityksen pohjana on kuitenkin viron ja suomen yhteinen itämerensuomalainen ja laajemmin uralilainen monituhatvuotinen menneisyys; suomi mainitaankin kirjassa arviolta joka kolmannella sivulla. Vaikka kirjassa on paljon purtavaa, se on kauttaaltaan helppolukuinen. Vanhat ja uudet tiedonjyvät viroksi esiteltyinä avaavat kerta toisensa jälkeen uusia näköaloja myös suomen kieleen.

Erityisen ansiokasta on, että teos sisältää kymmeniä havainnollisia taulukoita ja kuvioita, joista monet kuvaavat myös suomea edeltäneitä kantamuotoja ajanmukaisemmin ja tarkemmin kuin mitkään tähänastiset suomalaiset esitykset. Esimerkiksi kantasuomen taivutusmuodot esitetään parhaiten ja kattavimmin juuri tämän kirjan taulukoissa, ja niiden asteittainen kehitys nykyviroksi kuvataan esimerkein, jotka auttavat ymmärtämään molempien kielten eroja ja yhtäläisyyksiä. Runsaasti huomiota saavat myös kantasuomesta asti periytyvät murre-erot; muinaisen kantasuomalaisen yhtenäisyyden näyttää päättäneen muusta itämerensuomesta ensimmäisenä eriytynyt eteläviro, jonka suhde pohjoisviroon on ehtinyt vuosituhansien saatossa kehittyä mutkikkaaksi vyyhdeksi. 
Kielen muuttumista ei teoksessa esitetä niin automaattisena, tiedostamattomana kehityksenä kuin mikä äännehistoriaan keskittyville kielihistorian kuvauksille on usein luonteenomaista. Myös viron tietoinen kielenohjailu ja etenkin vuosisadan takainen kielenuudistus saavat ansaitusti huomiota: Parin sadan lähes tyhjästä keksityn sanan lisäksi yleiskieleen istutettiin onnistuneesti jopa kokonainen sija, essiivi; yritettiinpä instruktiiviakin. Superlatiivi tuotiin kokonaan uutena morfologisena kategoriana suomesta. Suomen mallin mukaan luotiin myös sittemmin täysin vakiintunut tarkoitusta ilmaiseva ei-finiittinen maks-muoto, minkä seurauksena vanhan analyyttisen et saada kõige paremaks -tyyppisen ilmaisun sijaan ja rinnalla on nyt aivan luonnollista sanoa myös samaa tarkoittava saamaks parimaks 'tullakseen parhaaksi', vaikka 1800-luvulla tällaisia muotoja ei ollut olemassakaan. Kaikkia viron puhekielen uudennoksia ja kielenhuoltajien kauhuja kirjassa ei kuitenkaan käsitellä, vaikka yhtymäkohdat suomeen jatkuisivat edelleen: esimerkiksi mõni-sanan partitiivi mõnda on reanalysoitu perusmuodoksi, jonka pohjalta muodostetaan ei-toivottuja analogiamuotoja, kuten mõndadel pro mõnedel, melko samaan tapaan kuin suomen montaa, joka sittemmin on osin hyväksytty osaksi yleiskieltä.

\section{Varaa parantamiseenkin}

Kokonaisuudessaan varsin mainio Eesti keele ajalugu voisi toki olla vieläkin parempi. Kirjan sisältämää tietomäärää olisi tuskin kukaan kyennyt esittämään yksin, mutta viidellä kirjoittajalla on vähintään viisi eri käsitystä kielen kehityksestä. Paikoin tuloksena on pieniä epäkohtia, jotka himmentävät kirjan sanomaa.

Viron kielen historiaan keskittyvän teoksen kokonaissanoman kannalta hieman toissijainen, mutta yleisen uralistiikan kannalta tavattoman keskeinen on kysymys kielikunnan taksonomiasta eli siitä, miten uralilainen kantakieli on jakautunut nykyisiksi kieliksi. Lyhin, objektiivisin vastaus kysymykseen on, että tätä ei tiedetä. On myös selvää, että tunnetuin näkemys on perinteinen binäärinen esitys, jossa kielikunta jakautuu ensin suomalaisugrilaiseen ja samojedilaiseen haaraan, suomalais-ugrilainen siitä edelleen länteen haaroen suomalais-permiläisiin ja ugrilaisiin kieliin, ja niin edelleen. On kuitenkin harmi, että tämä näkemys esitetään yhä niin laajasti hyväksyttynä, että kilpailevana näkemyksenä mainitaan yhdessä alaviitteessä (s. 342) - ainoastaan Jaakko Häkkisen $(2007,2012)$ "vain" äänteenmuutoksiin perustuva vaihtoehtoinen esitys, joka kuitenkin torjutaan saman tien. Torjuntaa perustellaan ainoastaan indoeuropeisti Frederik Kortlandtin (2019) nelisivuisella 
kirjoituksella, jossa Häkkiseen tai muiden vaihtoehtojen esittäjiin (esim. jo Kaisa Häkkinen 1983: 379-386; 1984) ei viitata lainkaan.

Vaikka Eesti keele ajalugu systemaattisuudessaan osoittaa, että binäärisellä mallilla on edelleen mahdollista operoida, reilumpaa olisi kuitenkin ollut kertoa aiheeseen vihkiytymättömille kielihistorian käsikirjan lukijoille paljon selvemmin, että tässä teoksessa kritiikittä kannatettu käsitys on viime vuosikymmenten aikana menettänyt sijaa monille vaihtoehtoisille näkemyksille siinä määrin, että alan aktiivisimpien asiantuntijoiden keskuudessa mistään yleisesti hyväksytystä taksonomiasta ei voida tällä hetkellä puhua (esim. Aikio, tulossa; Saarikivi, tulossa). Etenkin viron sanastokerrostumien esittely vaikuttaisi aivan toisenlaiselta - ja paljon ajanmukaisemmalta - jos vanha binäärinen malli olisi esitetty mallina mallien joukossa (ks. myös Junttila 2013). Tämä ei tietenkään tarkoita, että vanha käsitys on varmasti väärä ja uudet käsitykset oikeita; alan käsikirjaan kuuluisi ennen kaikkea tieto, että yleisesti jaettua käsitystä ei nykyään ole.

Suoranaisista ristiriidoista on kyse silloin, kun kummallisimpiakin väitteitä on haluttu esitellä diplomaattisesti niiden ongelmallisuutta korostamatta. Virossa erityisen uhkarohkeita kielihistoriallisia näkemyksiä on esittänyt Ago Künnap, jonka heittoja kuitenkin esitellään kirjassa hämäävän neutraalisti: Esimerkiksi etelävirossa ja osin myös pohjoisviron itämurteissa tavattavia kieltoverbin menneen ajan muotoja pidetään yleisesti - ja perustellusti - ikivanhana perintönä, jolla on vastineita liivissä ja etäsukukielissä (esim. eteläviron lausekeparia ei tiiä 'ei tiedä' : es tiiä 'ei tiennyt' vastaa luulajansaamen ij diede : ittjij diede). Viron morfologian historiaa kuvaavat Prillop ja Saar (s. 187) kuitenkin referoivat vakavissaan Künnapin esityksiä, joiden mukaan tällaisia muotoja tulee pitää viron myöhäsyntyisen, supistumaverbien taivutuksesta mallinsa saaneen $s i$-imperfektin luomina uusina analogiamuotoina. Aivan perusteetonta palstatilaa saa Künnapin ajatus, että itämerensuomen *n-tunnuksisen genetiivin taustalla ei olisi yhtäältä uralilaisen kantakielen genetiivi *- $n$ ja toisaalta siihen sulautunut akkusatiivi *-m (s. 191).

Vaikka tällaiset hypoteesit syystä tai toisesta uskottaisiinkin, Eesti keele ajalugu kuvaa näitä aiheita sen verran ristiriitaisesti, että teos itsessäänkin voi saada tarkimmat lukijat hämmentymään: kielihistorian tutkimusmenetelmiä johdantoluvussa esitellessään Prillop ja Viitso varta vasten mainitsevat $* n$-genetiivin ja $* m$-akkusatiivin rekonstruoimisen oppikirjaesimerkkinä vertailevan menetelmän käytöstä (s. 37). Samaan vanhaan totuuteen 
viitataan myös Prillopin kirjoittamassa fonologialuvussa (s. 114) sekä Prillopin ja Saaren kirjoittamassa morfologialuvussa (s. 188). Selvyyden vuoksi korostettakoon, että oppikirjaesimerkiksi ja ylipäänsä esimerkiksi kenties varmimmin rekonstruoitavista taivutusmorfeemeista $* n$-genetiivi ja *m-akkusatiivi sopivat siksi, että niiden ero on säilynyt aivan selvästi sekä kielikunnan läntisimmässä kielessä eteläsaamessa (guelie 'kala' : guelien 'kalan (gen.)' : gueliem 'kalan (akk.)') että paljon idempänä marissa (kol : kolân : kolâm). ${ }^{2}$ Kielihistorian periaatteet tuntevalle tässä ei pitäisi olla enää mitään epäilemistä, joten mainitut teoriat sopivat pikemminkin oppikirjaesimerkiksi siitä, mihin päädytään, jos historiallisen kielentutkimuksen pääperiaatteet hylätään.

\section{Lopuksi}

Virittäjän yhdeksännenkolmatta vuosikerran päätteeksi lehden perustajiin kuulunut pitkäaikainen päätoimittaja E. A. Tunkelo (1925: 153) esitteli yhä nykyäänkin ilmestyvän Viron kansallismuseon vuosikirjan, Eesti Rahva Muuseumi aastaraamatun, ensimmäistä numeroa todeten, että kyseessä oli "ilahduttava näyte kansallisten tieteiden elpymisestä nuoren, toimeliaan veljeskansamme monien virkeiden pyrintöjen joukossa”. Samoin tuntein voi ihastella myös 95 vuotta myöhemmin ilmestynyttä ensimmäistä viron kielen historian yleisesitystä, jonka taustalla on Virossa viime vuosikymmeninä verraten näkyvän roolin saanut oman kielen historian tutkimus. Vaikka virolaisen kielihistorian pioneereja olivat suomalaiset E. N. Setälä, Heikki Ojansuu ja Lauri Kettunen, itämerensuomalaisten kielten historian tutkimuksessa puhaltaa tätä nykyä myös kohtalainen etelätuuli: kattavin ja ajanmukaisin suomenkin äänne- ja muotohistorian yleisesitys tulee Tartosta, jossa esimerkiksi kirjoittajakuntaan kuuluva Karl Pajusalu toimii viron kielen historian ja murteiden professorina eli tehtävässä, jolle suomalaisessa fennistiikassa ei ole vastinetta. Suomessa kielihistorian tutkimus yleisestikin on keskittynyt pääasiassa toisten oppituolien alaisuuteen, mutta Eesti keele ajalugu on oiva osoitus siitä, että kansalliskielen historian kokonaisvaltaisella tutkimuksella voisi olla tämänhetkistä tukevampi jalansija myös nykySuomessa.

\footnotetext{
${ }^{2}$ Tarkasti toimitetussa teoksessa on - kattavaa mutta tavallista huolimattomammin laadittua lähdeluetteloa lukuun ottamatta - melko vähän kirjoitusvirheitä, mutta esimerkiksi sivulla 188 esitettyjen marin muotojen "kolên" ja "kolêm" tulee olla kolân ja kolâm.
} 


\section{Lähteet}

Aikio = LuObBAl SÁmmol SÁMmol ÁnTe (AnTE Aikio) (tulossa): Proto-Uralic. - Marianne Bakró-Nagy, Johanna Laakso \& Elena Skribnik (toim.), The Oxford guide to the Uralic languages. Oxford: Oxford University Press.

HAKULINEN, LAURI 1941: Suomen kielen rakenne ja kehitys. Ensimmäinen osa. Ä̈̈nne- ja muoto-oppia. Helsinki: Otava.

HÄKKINEN, JAAKKO 2007: Kantauralin murteutuminen vokaalivastaavuuksien valossa. Pro gradu -tutkielma. Helsinki: Helsingin yliopisto.

- 2012. After the protolanguage: invisible convergence, false divergence and boundary shift. - Finnisch-Ugrische Forschungen 61 s. 7-28. https://doi.org/10.33339/fuf.85674

HÄKKINEN, KAISA 1983: Suomen kielen vanhimmasta sanastosta ja sen tutkimisesta.

Suomalais-ugrilaisten kielten etymologisen tutkimuksen perusteita ja metodiikkaa. Turku: Turun yliopisto.

— 1984: Wäre es schon an der Zeit, den Stammbaum zu fällen? - Ural-Altaische Jahrbücher. Neue Folge 4 s. 1-24.

JUNTTILA, SANTERI 2013: Viron sanojen lähteillä. - Virittäjä 117 s. 136-143.

KASIK, REET 2011: Stahli mantlipärijad. Eesti keele uurimise lugu. Tartu: Tartu Ülikooli Kirjastus.

— 2015: Sõnamoodustus. Eesti keele varamu I. Tartu: Tartu Ülikooli Kirjastus.

KETTUNEN, LAURI 1917: Viron kielen äännehistorian pääpiirteet. Helsinki: Suomalaisen Kirjallisuuden Seura.

KORTLANDT, FREDERIK 2019: On the reconstruction of Proto-Uralic. - Santeri Junttila \& Juha Kuokkala (toim.), Petri Kallio rocks. Liber semisaecularis 7.2.2019 s. 11-14. Helsinki: Kallion Etymologiseura.

LAANEST, ARVO 1982: Einführung in die ostseefinnischen Sprachen. Hamburg: Buske.

LEHTINEN, TAPANI 2007: Kielen vuosituhannet. Suomen kielen kehitys kantauralista varhaissuomeen. Helsinki: Suomalaisen Kirjallisuuden Seura.

METSMÄGI, IrIS - SEDRIK, MEELI - SOOSAAR, SVEN-ERIK (toim.) 2012: Eesti etümoloogiasõnaraamat. Tallinn: Eesti Keele Sihtasutus.

NIINIVAARA, EEVA 1961: Virittäjässä 1897-1959 julkaistuja viron kieleen ja kulttuuriin liittyviä kirjoituksia sekä virolaisten kirjoittajien kirjoituksia. - Virittäjä 65 s. 107-114.

— 1982: Virittäjän Viron-bibliografiaa 1960-80. - Virittäjä 86 s. 69-74

— 1991: Virittäjän Viron-bibliografiaa 1981-90. - Virittäjä 95 s. 453-456. 
RÄTSEP, HUNO 1994: Viron ja suomen kielen tutkimuksen yhteisiä suuntaviivoja. - Virittäjä 98 s. $267-273$.

SAARIKIVI, JANNE 2011: Tarpeellista perustietoa - mutta kuinka ajanmukaisesti? - Virittäjä 115 s. 294-303.

- (tulossa): The divergence of Proto-Uralic and its offspring: A descendant reconstruction. Marianne Bakró-Nagy, Johanna Laakso \& Elena Skribnik (toim.), The Oxford guide to the Uralic languages. Oxford: Oxford University Press.

Tunkelo, E. A. 1925: Eesti Rahva Muuseumi Aastaraamat I. - Virittäjä 29 s. 153-154. 